Diagnostic Accuracy Study

\title{
Comparison of Clonazepam Compliance by Measurement of Urinary Concentration by Immunoassay and LC-MS/MS in Pain Management Population
}

Robert West, MS, Amadeo Pesce, PhD, Cameron West, PhD, Bridgit Crews, PhD, Charles Mikel, PhD, Perla Almazan, MT, Murray Rosenthal,DO, and Sergey Latyshev, MS

From: Millennium Laboratories Research Institute, San Diego,

CA

Dr. Mike is Chief Scientist at Millennium Laboratories Research Institute, San Diego, CA. Dr. Rosenthall is Chief Medical Officer, Millennium Laboratories Research Institute, San Diego, CA. Ms. Almazan, MT is Associate Director Clinical Operations, Millennium Laboratories Research Institute, San Diego, CA. Dr. West is Colaboratory Director Millennium Laboratories Research Institute, San Diego, CA. Dr. Pesce is CoLaboratory Director, Millennium Laboratories Research Institute,

San Diego, CA Dr. Crews is the Mass Spectrometry Specialist at Millennium Laboratories Research Institute, San Diego, CA. Latyshev is Mass Spectrometry Specialist at Millennium Laboratories Research Institute, San Diego, CA.

Address correspondence: Cameron West, Ph.D. Millennium Laboratories 16981 Via Tazon

San Diego CA 92127 E-mail: cwest@ becausepainatters.com

Disclaimer: There was no external funding in the preparation of this manuscript. Conflict of interest: None.

Manuscript received: $12 / 15 / 2009$

Revised manuscript received: 01/06/2010

Accepted for publication: 01/07/2010

Free full manuscript: www.painphysicianjournal.com
Background: Physicians determine patient compliance with their medications by use of urine drug testing. It is known that measurement of benzodiazepines is limited by immunoassay specificity and cutoff limits and therefore does not offer physicians an accurate picture of their patients' compliance with these medications. A few studies have used lower cutoffs to demonstrate patient compliance.

Objectives: To define more appropriate cutoffs for compliance monitoring of patients prescribed clonazepam as determined using immunoassay and liquid chromatography-tandem mass spectrometry (LC-MS/MS).

Study Design: A diagnostic accuracy study of the urinary excretion of clonazepam.

Methods: Millennium Laboratories performed measurements on the urinary excretion of pain patients prescribed clonazepam as the indicator test. This benzodiazepine was chosen because it forms one major metabolite, 7-aminoclonazepam which is specific for that drug. Patients whose only benzodiazepine medication was clonazepam were selected as the test population.

The Millennium Laboratories test database was filtered first to select patients on clonazepam, then a second filter was used to eliminate patients with any other listed benzodiazepine medications. Samples were tested using the Microgenics DRI ${ }^{\circledR}$ benzodiazepine assay with a $200 \mathrm{ng} / \mathrm{mL}$ cutoff. The same samples were quantitatively assessed for 7-aminoclonazepam by LC-MS/MS with a cutoff of $40 \mathrm{ng} / \mathrm{mL}$. The results from the immunoassay were scored as positive or negative while the quantitative results from the LC-MS/MS were also scored as positive or negative depending upon their concentration.

Results: Samples from 180 patients met these medication criteria. The positivity rates were $21 \%$ (38 samples) by immunoassay. The positivity rate was $70 \%$ (126 samples) if the LC-MS/MS cutoff was set at $200 \mathrm{ng} / \mathrm{mL}$. However, the positivity rate was $87 \%$ (157 samples) if the LC-MS/MS was set at $40 \mathrm{ng} / \mathrm{mL}$. Concentration distributions revealed a significant fraction (7\%) in the $40-100 \mathrm{ng} / \mathrm{mL}$ range.

Limitations: A limitation of the study was the inability to measure lower than $40 \mathrm{ng} / \mathrm{mL}$. There may be another fraction of the population that was positive below the cutoff value.

Conclusions: The difference in positivity rate between the immunoassay and the LC-MS/MS result showed that the nominal $200 \mathrm{ng} / \mathrm{mL}$ cutoff of the immunoassay did not apply to 7-aminoclonazepam. This low immunoassay positivity rate is inconsistent with the manufacturer's published cross reactivity data for clonazepam and 7-aminoclonazepam. These data illustrate the limitations of using a $200 \mathrm{ng} /$ $\mathrm{mL}$ cutoff to monitor clonazepam compliance and suggest that a cutoff of $40 \mathrm{ng} / \mathrm{mL}$ or less is needed to reliably monitor use of this drug.

Key words: Clonazepam, 7-aminoclonazepam, pain management, LC-MS/MS, immunoassay, patient compliance

Pain Physician 2010; 13:71-78 
P ain management patients are often prescribed benzodiazepines as well as opiates as part of their regimen of pain management medication (1-6). The drug clonazepam (Klonopin ${ }^{\circledR}$ ) is one of the most frequently prescribed Schedule IV medications in the United States and is used for the treatment of anxiety and epilepsy (7). Potential problems associated with improper use or abuse of this drug include physical and psychological dependence, suicidal thoughts or actions, worsening of depression, sleep disorders, and aggression $(8,9)$. As with many benzodiazepines, Klonopin can have drug interactions and can cause a number of unwanted physical symptoms upon withdrawal such as faintness, dizziness, sweating, tremors, etc. $(10,11)$.

Patients are tested to ensure compliance with this group of drugs. Failure to observe the presence of the prescribed benzodiazepine can lead to patient dismissal with dire consequences for their pain control. Therefore the analyst is challenged to provide accurate information regarding compliance with benzodiazepine medications.

Fraser (12) has pointed out that there has been an evolution in the prescription use of benzodiazepines in that "the cutoff values for benzodiazepines were established many years ago when most benzodiazepines were prescribed in doses of 5 to $20 \mathrm{mg} / \mathrm{d}$ ". As a consequence, lower concentrations of this class of drugs should be found on urine drug screening. Therefore, the current $200 \mathrm{ng} / \mathrm{mL}$ cutoff is most likely too high to establish patient compliance for benzodiazepines. Few studies have been conducted to establish the appropriate cutoff level for benzodiazepines (13-16).

Clonazepam is structurally in the benzodiazepine class and its metabolism results in the products 7-aminoclonazepam and 7-acetamidoclonazepam. Less than 0.5 percent of the drug is eliminated as the parent or unchanged drug (17). The cross-reactivity of the 7-aminoclonazepam varies considerably depending upon the immunoassay vendor. Many vendors do not list the cross-reactivity of the 7-aminoclonazepam; rather, they only describe the parent drug (17). Several of those show that 7-aminoclonazepam has a cross-reactivity of less than 2 percent in their "benzodiazepine immunoassay." With this in mind, we chose to measure the excreted concentrations of 7-aminoclonazepam from patients prescribed clonazepam. To define the cutoff, we compared our immunoassay results with those from Liquid Chromatography-Tandem Mass Spectrometry (LC-MS/MS) performed as previously described (18).

\section{Methods}

\section{Participants}

Participants were patients being treated for pain who were given urine drug testing to monitor compliance as part of their standard treatment protocol. No patients were harmed in this study. This human research was approved by the Aspire Independent Review Board 9320 Fuerte Dr. Suite 105, La Mesa, CA, 91941.

\section{Test Methods}

This cohort was tested using the Microgenics DRI@ benzodiazepine assay with a $200 \mathrm{ng} / \mathrm{mL}$ cutoff on Olympus AU640 and AU5400 analyzers (19). The manufacturer lists the concentration at which the assay will be positive for 7-aminoclonazepam and clonazepam at 200 and $250 \mathrm{ng} / \mathrm{mL}$ respectively. No mention is made of the glucuronidated forms. Quantitative analysis of 7-aminoclonazepam was performed on the same samples by LC-MS/MS with a cutoff of $40 \mathrm{ng} / \mathrm{mL}$ using the Agilent model 6410 triple quad in MRM mode. Samples were prepared for MS analysis using a simple "dilute and shoot" technique that incorporates glucuronidase hydrolysis. Creatinine was measured for each sample to insure that there was no adulteration.

The LC-MS/MS procedures were performed on Agilent 6410 instruments (Agilent Corporation, 5301 Stevens Creek Blvd, Santa Clara CA 95051, USA). The method was that described by Moore, Coulter and Crompton as modified by Millennium Laboratories $(18,20,21)$.

An Agilent 1200 series binary pump SL LC system, well plate sampler, thermostatted column compartment paired with an Agilent triple Quadrupole mass spectrometer and Agilent Mass Hunter software were used for analysis of 7-aminoclonazepam (18). Chromatographic separation was performed using an acetonitrile, formic acid, water gradient running at $0.4 \mathrm{~mL} / \mathrm{min}$ and a $2.1 \mathrm{x}$ $50 \mathrm{~mm}, 2.7 \mu \mathrm{m}$ Ascentis Express $\mathrm{C} 18$ column (Supelco, Bellefonte, PA). Mobile phase $A=0.1 \%$ formic acid in water, $B=0.1 \%$ formic acid in acetonitrile, and column temperature was set to $50^{\circ} \mathrm{C}$. Samples were prepared for injection by incubating $25 \mu \mathrm{L}$ of urine with 50 units of glucuronidase b-Glucuronidase Type L-II from Patella vulgata (keyhole limpet) Sigma Product number G 8132 (Sigma-Aldrich Corp 3050 Spruce Street Saint Louis, MO 63103 ) in $50 \mu \mathrm{L} 0.4 \mathrm{M} \mathrm{pH} 4.5$ acetate buffer for 3 hours at $65^{\circ} \mathrm{C}$. The samples were then diluted with $100 \mu \mathrm{L}$ of acetonitrile and filtered using Millipore MultiScreen Solvinert filter plates. Five $\mu \mathrm{L}$ of this material was injected into the LC-MS/MS. 
All spectra were collected using positive electrospray ionization. The optimized instrumental parameters were as follows: gas temperature, $350^{\circ} \mathrm{C}$; drying gas, 12 L/min; nebulizer gas (nitrogen), 35 psi ( 24,100 $\mathrm{Pa}$ ); capillary voltage, $3000 \mathrm{~V}$; fragmentor voltage, $60 \mathrm{~V}$. Multiple reaction monitoring (MRM) mode was used for quantitation.

In MRM mode 2 transitions were used to identify and quantitate a single compound. A quantitative transition was used to calculate concentration based on the quantifier ion and a qualitative transition was used to ensure accurate identification of the target compound based on the ratio of the qualifier ion to the quantifier ion. The following quantitative transitions were used: 7aminoclonazepam: $\mathrm{m} / \mathrm{z} 286 \rightarrow 222$ with fragmentation voltage set to 120 volts, 7-aminoclonazepam-D4: $\mathrm{m} / \mathrm{z}$ $290 \rightarrow 226$ with fragmentation voltage set at 120 volts. The following qualitative transitions were used: 7-aminoclonazepam: $\mathrm{m} / \mathrm{z} 286 \rightarrow 121$ with collision energy set to 25 volts. Dwell times were set to $50 \mathrm{msec}$.

A 4-point calibration curve was created by using the following concentrations of 7-aminoclonazepam: $40 \mathrm{ng} / \mathrm{mL}, 100 \mathrm{ng} / \mathrm{mL}, 3200 \mathrm{ng} / \mathrm{mL}$, and $6400 \mathrm{ng} / \mathrm{mL}$. The calibration curve was established as a linear fit of the four points and forcing the curve to pass through the origin. The accepted accuracy for calibrators was $\pm 20 \%$ of the target value and the coefficient of determination (R2) of the linear fit was required to be greater than or equal to 0.95 as verification of linearity and goodnessof-fit. The imprecision (CV) as determined by the quality control specimens set at 80 and $900 \mathrm{ng} / \mathrm{mL}$ were $13 \%$ and $11 \%$.

HPLC grade $\mathrm{H} 2 \mathrm{O}$, acetonitrile, methanol, and formic acid were obtained from VWR (Westchester, PA). 7-aminoclonazepam and 7-aminoclonazepam D4 were obtained from Cerriliant Corp (Round Rock, Texas). The deuterated internal standard was diluted to 1,000 $\mathrm{ng}$ per $\mathrm{mL}$ by adding it to synthetic urine (Microgenics corp., Fremont CA).

The LC-MS/MS limit of quantitation for 7-aminoclonazepam was set from the calibration curve at $40 \mathrm{ng} /$ $\mathrm{mL}$. The linear range of values for 7-aminoclonazepam was from 40 to $100,000 \mathrm{ng} / \mathrm{mL}$.

The assay was tested for interferences against a library of 120 representative drugs and metabolites encountered in abuse, therapeutic treatment, and commonly used over the counter drugs (Table 1). Certified samples of these drugs were obtained from Cerrilliant Corp. and diluted in synthetic urine to the concentrations listed in Table 2. The potentially interfering drugs were treated, chromatographed, and analyzed using the parent and daughter ion settings for 7-aminoclonazepam. The potentially interfering drugs were first tested to determine if they could be detected in the assay.

The listed drug levels produced no false positives or chromatographic interferences in the form of peak broadening, shoulders, or q-value distortion for any of our current LC-MS/MS confirmatory assays at the listed concentrations. This confirmed the specificity of the analytical procedure and the mass ion settings and Q-values used to validate the presence of the 7-aminoclonazepam.

False negative results were assessed using solutions spiked with the confirmatory analyte at the lower limit of quantitation (LLOQ) and the questionable interferant at 50,000 ng/mL (Table 2). The reported quantitative values were correctly measured at the LLOQ within $20 \%$.

\section{Statistical Methods}

A retrospective analysis of the Millennium Laboratories test database was conducted by members of Millennium Laboratories Research Institute over a 2-month period to compare the ability of immunoassay and LC/MS/MS to detect clonazepam in a pain patient population. This allowed an evaluation of immunoassay responses representative of clonazepam and its metabolites that were not influenced by other benzodiazepines.

The test data were filtered to include patients with prescriptions for clonazepam and exclude samples containing oxazepam, nordiazepam, temazepam, alphahydroxyalprazolam, and lorazepam.

One-hundred and eighty sequential urine specimens from 180 pain patients that listed clonazepam as a prescribed drug were selected for analysis of 7aminoclonazepam. All patients were in treatment for chronic pain. No other exclusion criteria were used.

\section{Results}

Figure 1 illustrates specimen selection flow chart.

We found the assay to be linear over the calibration range used for this study. All of the 50 or more assays used to gather the data presented in this work were from calibration curves with R2 values greater than 0.95 . Virtually all the curves were found to have $\mathrm{R} 2$ values of 0.99 . Matrix effects were found to be within the acceptable range with ion suppression less than $50 \%$ based on the ion response of the internal stan- 
Table 1. Drug levels tested for interference.

\begin{tabular}{|c|c|c|c|c|c|c|c|}
\hline Drug & $\mathbf{n g} / \mathbf{m L}$ & Drug & $\mathbf{n g} / \mathbf{m L}$ & Drug & $\mathbf{n g} / \mathbf{m L}$ & Drug & $\mathbf{n g} / \mathbf{m L}$ \\
\hline 6-monoacetylmorphine & 1,280 & ketamine & 500 & & & & \\
\hline 11-nor-9-carboxy THC & 512 & lamotrigene & 5,000 & Clozapine & 500 & $\begin{array}{l}\text { faxine } \\
\text { o-desmetnylventa- }\end{array}$ & 500 \\
\hline 6-acetyl morphine & 5 & lidocaine & 1,000 & cocaethylene & 100 & olanzapine & 600 \\
\hline 7-amino clonazepam & 125 & lorazepam & 5,120 & Cocaine & 100 & oxezepam & 5,120 \\
\hline 7-amino flunitrazepam & 125 & loxapine & 250 & Codeine & 6,400 & oxycodone & 6,400 \\
\hline acetaminophen & 25,000 & maprotiline & 1,250 & cyclobenzaprine & 100 & oxymorphone & 6,400 \\
\hline alpha-OH-alprazolam & 2,560 & MCPP & 250 & desalkyflurazepam & 500 & paroxetine & 500 \\
\hline Alprazolam & 250 & MDA & 100 & desipramine & 500 & pentazocine & 500 \\
\hline amantadine & 250 & MDMA & 12,800 & Desmethyl doxepin & 500 & phencyclidine & 640 \\
\hline amitiptyline & 500 & meclizine & 600 & desmethylcitalopram & 250 & phenobarbital & 5,000 \\
\hline amoxapine & 600 & meperidine & 500 & desmethylclomipramine & 500 & phentermine & 500 \\
\hline amphetamine & 12,800 & meprobamate & 6,400 & desmethyldoxepin & 600 & phenytoin & 5000 \\
\hline Antipyrine & 1000 & mesoridazine & 500 & desmethylsertraline & 250 & promethazine & 500 \\
\hline atomoxetine & 500 & methadone & 6,400 & dextromethorphan & 500 & propoxyphene & 12,800 \\
\hline benzocaine & 500 & methamphetamine & 12,800 & Diazepam & 500 & pseudoephedrine & 1,250 \\
\hline benzoylecgonine & 3,200 & methylphenidate & 50 & Diltiazem & 500 & quetiapine & 250 \\
\hline bropheniramine & 50 & metoclopramide & 500 & diphenhydramine & 500 & sertailine & 500 \\
\hline bupivacaine & 500 & midazolam & 125 & Doxepin & 500 & strychnine & 500 \\
\hline buprenorphine & 1,280 & midazolam & 100 & doxylamine & 500 & temazepam & 6,400 \\
\hline Bupropion & 500 & mirtazepine & 250 & Duloxetine & 500 & thioridazine & 500 \\
\hline Bupropion metabolite & 1,000 & Morphine & 6,400 & ecgonine methyl esther & 500 & topiramate & 5,000 \\
\hline Butalbital & 5,000 & Morphine & 50 & EDDP & 12,800 & tramadol & 3,200 \\
\hline carbamazepine & 5,000 & $\begin{array}{l}\text { Morphine-3- } \\
\text { glucuronide }\end{array}$ & 250 & Fentanyl & 256 & trazodone & 1,000 \\
\hline carisoprodol & 6,400 & norbuprenorphine & 1,280 & flunitrazepam & 125 & triazolam & 125 \\
\hline chlordiazepoxide & 125 & nordiazepam & 5,120 & Fluoxetine & 500 & trimethobenza- & 500 \\
\hline chlorpheniramine & 500 & norfentanyl & 1,024 & Flurazepam & 125 & trimethoprim & 500 \\
\hline chlorpomazine & 500 & norfluoxetine & 500 & hydrocodone & 6,400 & varapamil & 500 \\
\hline Citalopram & 250 & normeperidine & 500 & hydromorphone & 6,400 & venlafaxine & 500 \\
\hline clomipramine & 125 & norpropoxyphene & 12,800 & Ibuprofen & 25,000 & zolpidem & 250 \\
\hline clonazepam & 500 & nortriptyline & 500 & imipramine & 500 & zopiclone & 125 \\
\hline
\end{tabular}

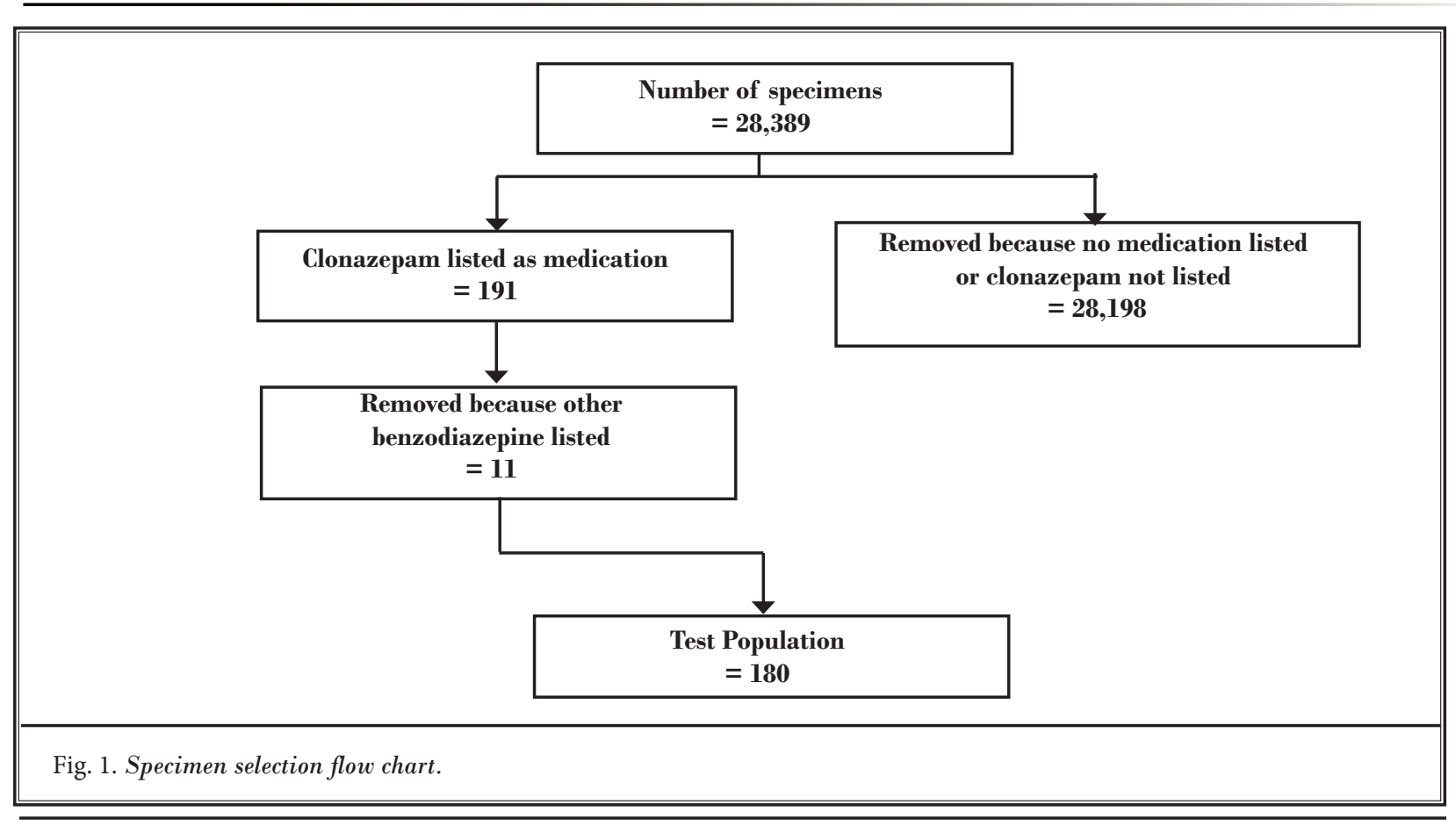


Table 2. Drugs that did not cause interference.

\begin{tabular}{|l|c|c|}
\hline \multicolumn{1}{|c|}{ Drug } & No False Positives Concentration (ng/mL) & No False Negatives Concentration (ng/mL) \\
\hline Acetaminophen & 100,000 & 50,000 \\
\hline Paraxanthine & 100,000 & 50,000 \\
\hline Naproxen & 100,000 & 50,000 \\
\hline Ibuprofen & 100,000 & 50,000 \\
\hline 6-Acetylcodeine & 100,000 & 50,000 \\
\hline Norcodeine & 100,000 & 50,000 \\
\hline dihydrocodeine & 100,000 & 50,000 \\
\hline Normorphine & 100,000 & 50,000 \\
\hline Noroxycodone & 100,000 & 50,000 \\
\hline Phenylpropanolamine & 100,000 & 50,000 \\
\hline MDEA & 100,000 & 50,000 \\
\hline MDA & 100,000 & 50,000 \\
\hline Ephedrine & 100,000 & 50,000 \\
\hline psuedoephedrine & 100,000 & 50,000 \\
\hline phentermine & 100,000 & 50,000 \\
\hline
\end{tabular}

dard of the patient samples versus the calibration and control internal standard ion responses. As described in the methods section above, there were no interferences from common prescription and over the counter drugs.

We determined the 7-aminoclonazepam concentrations in those specimens where the only listed benzodiazepine was clonazepam. Using the LC-MS/MS analytical data as the gold standard, the distribution of the urinary concentrations are presented in Fig. 2. Please note the bin size was changed after the $500 \mathrm{ng} / \mathrm{mL}$ mark. It is clear that there is a wide distribution of values from $41 \mathrm{ng} / \mathrm{mL}$ to $6,000 \mathrm{ng} / \mathrm{mL}$. The mean, median, and standard deviation were $892 \mathrm{ng} / \mathrm{mL}, 538 \mathrm{ng} / \mathrm{ml}$, and $1,005 \mathrm{ng} / \mathrm{mL}$ respectively.

Of the 180 samples only $21 \%$ (38 samples) were positive by immunoassay. By contrast, 70\% (126 samples) were positive for the metabolite by LC-MS/MS when the same nominal $200 \mathrm{ng} / \mathrm{mL}$ cutoff was used.

The difference between the $21 \%$ positivity rate observed by immunoassay and the $70 \%$ positivity rate observed by LC-MS/MS indicates that the immunoassay is not finding 7-aminoclonazepam at this nominal 200 $\mathrm{ng} / \mathrm{mL}$ cutoff. However, the low immunoassay positivity rate relative to that of Mass Spectrometric testing is inconsistent with the manufacturer's published cross reactivity data for clonazepam and 7-aminoclonaze- pam (14). However, the positivity rate increases to $87 \%$ when the LC-MS/MS cutoff is lowered to $40 \mathrm{ng} / \mathrm{mL}$. The difference between the $70 \%$ and $87 \%$ positivity rates is due to the application of 2 different cutoffs. Further, the concentration distributions plotted in Figure 2 reveal a significant fraction (7\%) of the urines had 7-aminoclonazepam in the $40-100 \mathrm{ng} / \mathrm{mL}$ range.

\section{Discussion}

Compliance is a major concern of physicians treating patients for chronic pain $(2,4,5)$. They rely on laboratories to provide accurate data to help them detect diversion as well as non-compliance. This study was limited to documenting compliance with patients prescribed clonazepam; the study did not consider examining patients taking the drug without prescription. Immunoassays are used as the initial screen before confirmation. In this study, we observed that our immunoassay only detected clonazepam use in $21 \%$ of the patients who had reported taking clonazepam as part of their treatment regime, so a better method is needed. In contrast, in this study the more accurate and sensitive LC-MS/MS procedure indicated that $87 \%$ were compliant, and therefore this is the preferred procedure.

Even with the lower LC-MS/MS cutoff $(40 \mathrm{ng} / \mathrm{mL})$ compared to the nominal $200 \mathrm{ng} / \mathrm{mL}$, we observed that 23 of the 180 patients, or $13 \%$ were possibly non- 


\section{Frequency Distribution of 7-aminoclonazepam Concentration in Specimens}

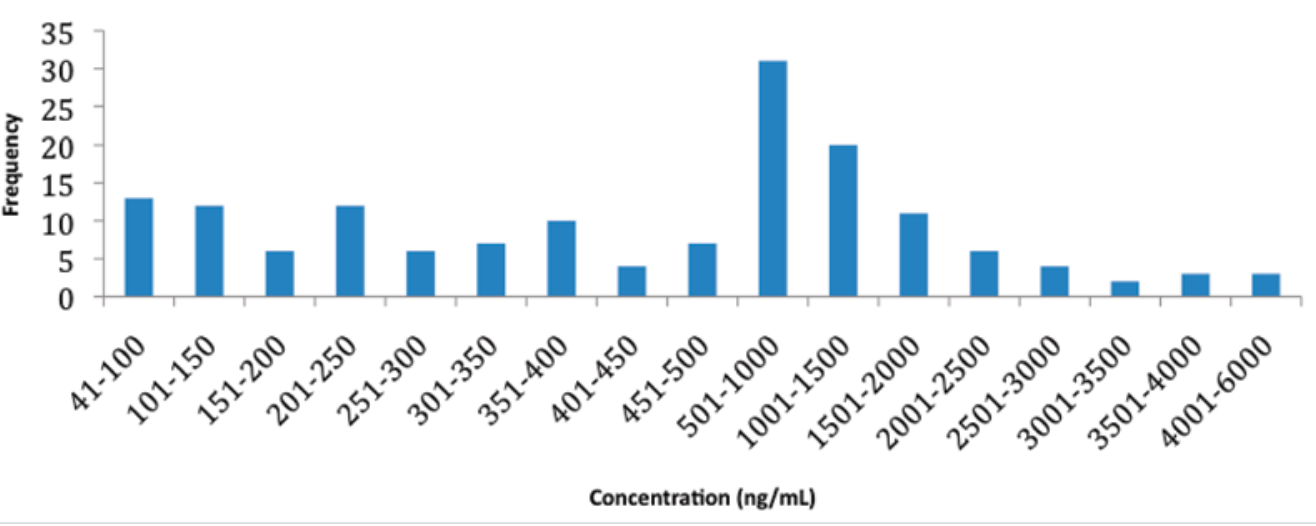

Fig. 2. Frequency distribution of 7-aminoclonazepam concentration in selected specimens.

The Y-axis is the number of specimens within the specified concentration range. The $X$-axis is the bin size for the test specimens. From $0-500 \mathrm{ng} / \mathrm{mL}$ the bin size is $50 \mathrm{ng} / \mathrm{mL}$. From $500-4000 \mathrm{ng} / \mathrm{mL}$ the bin size is $500 \mathrm{ng} / \mathrm{mL}$.

compliant. The question remains as to whether the 40 $\mathrm{ng} / \mathrm{mL}$ cutoff is most appropriate for this patient population. The median value of the drug was $538 \mathrm{ng} / \mathrm{mL}$ and $40 \mathrm{ng} / \mathrm{mL}$ represents approximately $1 / 13$ th of the median. The half-life of clonazepam is $19-60 \mathrm{hrs} \mathrm{(12).}$ Therefore, in the usual case, $40 \mathrm{ng} / \mathrm{mL}$ represents an approximate time of 4 half-lives or $80-240$ hrs after ingestion of the drug. By measuring the presence of the metabolite of clonazepam at $40 \mathrm{ng} / \mathrm{mL}$, this would allow the treating physician to be certain that the patient had taken the drug within the last several days prior to testing. This could be valuable in a number of instances: in cases where the patient is on a very low dose, the lower cutoff helps validate their compliance. Another scenario might be where a normally compliant patient reports having taken the medication on the day of the test, but the results at low cutoff show that they did in fact take the drug but possibly several days earlier. This information might alert the physician to consider that the patient may be experiencing memory loss.

The poor reactivity of some benzodiazepines with immunoassays has been well documented $(15,16,22-25)$. Hydrolysis with beta-glucuronidase has been recommended to improve the sensitivity (14). However, most high-volume laboratories do not use a pre-treatment step, rather, immunoassay analysis on the undiluted urine is performed (26). In addition, it is well known that lowering the detection cutoff results in finding increased numbers of patients positive for test medications as well as illicit drugs $(27,28)$.

Bearing in mind that using a cutoff of $40 \mathrm{ng} / \mathrm{mL}$ this study only found $13 \%$ of the cohort to be "non-compliant," it can be estimated that by using an even lower cutoff even fewer patients would be classified as noncompliant. More studies are needed to decide on the best cutoff.

The limitations of this study include inability to measure lower levels; however, with the available technology this study meets the criteria of diagnostic accuracy studies and also meets the reporting guidelines (29-33).

\section{Conclusions}

A number of studies have been published describing patient medication compliance using the traditional methods of immunoassay followed by Mass Spectrometry confirmation. This study raises the question of whether those analyses were flawed because of the 
potential for false negative results by both the immunoassay's lack of reactivity with some benzodiazepines as well as the high cutoffs used for these studies. We show that testing by LC-MS/MS at low cutoffs provides an accurate indication of patient compliance when used to detect the presence of 7-aminoclonazepam.
Many more patients were compliant. By extension, it can be reasoned that the same techniques and instrumentation may be effective for establishing compliance with prescriptions for other medications used for the treatment of chronic pain.

\section{References}

1. Manchikanti L, Damron KS, McManus C, Barnhill R. Patterns of illicit drug use and opioid abuse in patients with chronic pain at initial evaluation: a prospective observational study. Pain Physician 2004; 7: 431-437.

2. Manchikanti L, Atluri S, Trescot AM, Giordano J. Monitoring opioid adherence in chronic pain patients: tools, techniques, and utility. Pain Physician. 2008; 11:S155-S180.

3. Manchikanti L, Manchukonda R, Pampati V, Damron KS. Evaluation of abuse of prescription and illicit drugs in chronic pain patients receiving short acting (hydrocodone) or long acting (methadone) opioids. Pain Physician 2005; 8: 257-261.

4. Trescot AM, Helm S, Hansen H, Benyamin R, Glaser SE, Adlaka R, Patel S, Manchikanti L. Opioids in the management of chronic non-cancer pain: An update of American Society of the Interventional Pain Physicians' (ASIPP) guidelines. Pain Physician 2008; 11:S5S62.

5. Manchikanti L, Singh A. Therapeutic opioids: A ten-year perspective on the complexities and complications of the escalating use, abuse, and nonmedical use of opioids. Pain Physician 2008; 11: S63-S88.

6. Trescot AM, Datta, S, Lee M, Hansen H. Opioid pharmacology. Pain Physician 2008; 11:S133-S153.

7. Most Commonly Prescribed Drugs. Blue Cross Blue Shield of Texas 2009. www. bcbstx.com/pdf/druglist.pdf

8. Manchikanti KN, Manchikanti L, Damron KS, Pampati V, Fellows B. Increasing deaths from opioid analgesics in the United States: An evaluation in an interventional pain management practice. J Opioid Manage 2008; 4:271-283.

9. Manchikanti L, Manchikanti KN, Pampati V, Cash, KA. Prevalence of side effects of prolonged low or moderate dose opi- oid therapy with concomitant benzodiazepine and/or antidepressant therapy in chronic non-cancer pain. Pain Physician 2009; 12:259-267.

10. Drugs.com Klonopin. www.drugs.com/ $\mathrm{pdr} /$ klonopin.html. Accessed 1/4/2010.

11. Charney DS, Mihic SJ, Harris RA. Hypnotics and sedatives. Ch. 16. In: Brunton LL, Lazo JS, \& Parker KL eds. Goodman and Gilman's The Pharmacological Basis of Therapeutics 11th Edition. McGraw Hill, New York 2006. p. 412.

12. Fraser AD. Psychotropic agents: the benzodiazepines. In Shaw LM, Kwong TC, Rosano TG, Orsolak PJ, Wolf BA, \& Magnani B (eds) The Clinical Toxicology Laboratory. Contemporary Practice Of Poisoning Evaluation. 2001. AACC Press. Washington, DC.

13. Beck O, Lafolie P, Hjemdahl P, Borg S, Odelius G, Wirbing P. Detection of benzodiazepine intake in therapeutic doses by immunoanalysis of urine: Two techniques evaluated and modified for improved performance. Clin Chem 1992; 38:271-275

14. Meatherall R. Optimal enzymatic hydrolysis of urinary benzodiazepine conjugates. J Anal Toxicol 1994; 18:382-384.

15. Fraser AD, Meatherall R. Comparative evaluation of five immunoassays for the analysis of alprazolam and triazolam metabolites in urine: Effect of lowering the screening and GC-MS cut-off values. J Anal Toxicol 1996; 20:217-223.

16. Meatherall R, Fraser AD. Comparison of four immunoassays for the detection of lorazepam in urine. Ther Drug Monit 1998; 20:673-675.

17. White RN, Black ML Pain Management Testing Reference. AACC Press 2008. Washington, DC.

18. Mikel C, Almazan P, West R, Pesce A., West C, Latyshev S, Crews B. LC-MS/ MS extends the range of drug analysis in pain patients. Ther Drug Monit 2009; 31:746-748.
19. Microgenics Product package inserts Microgenics Fremont CA. DAU DRI Benzodiazepine Assay.

20. Moore CM, Coulter C, Crompton K. Immunalysis Corp., Zumwalt, M., Agilent Technologies Inc. Determination of benzodiazepines in oral fluid using $\mathrm{lc} / \mathrm{ms} / \mathrm{ms}$. Agilent application. www. chem.agilent.com/Library/applications/5989-7074EN.pdf

21. Target Compound Identification And Quantitation Procedure. Agilent Technologies Inc., Santa Clara, CA [MSD ChemStation Data Analysis] Last Reviewed: Marc 20, 2002.

22. Fitzgerald R. Analytical Toxicology of the Benzodiazepines. Therapeutic Drug Monitoring and Toxicology 1995; 16:169-186.

23. Valentine J, Middleton R, Sparks C. Identification of urinary benzodiazepines and their metabolites: comparison of automated hplc and gc-ms after immunoassay screening of clinical specimens. Journal of Analytical Toxicology 1996; 20:416-424.

24. Beck O, Linn Z, Brodin K, Borg S, Hjemdahl P. The online screening technique for urinary benzodiazepines: Comparison with EMIT, FPIA, and GC-MS. J Anal Toxicol 1997; 21:554-557.

25. Kurisaki E, Hayashida M, Nihira M, Ohno Y, Mashiko H, Okano T, Niwa S, \& Hiraiwa K. Diagnostic performance of triage for benzodiazepines: Urine analysis of the dose of therapeutic cases. Journal of Analytical Toxicology 2005; 29:539-543.

26. Cone EJ, Caplan YH, Black DL, Robert T, Moser F. Urine drug testing of chronic pain patients: Licit and illicit drug patterns. Journal of Analytical Toxicology 2008; 32:530-543.

27. Hattab EM, Goldberger BA, Johannsen LM, Kindland PW, Ticino F, Chronister CW, Bertholf RL. Modification of 
screening immunoassays to detect sub-threshold concentrations of cocaine, cannabinoids, and opiates in urine: Use for detecting maternal and neonatal drug exposures. Ann Clin Lab Sci 2000; 30:85-91.

28. Fraser AD, Zamecnik J. Impact of lowering the screening and confirmation cutoff values for urine drug testing based on dilution indicators. Ther Drug Monit 2003; 25:723-727.

29. Manchikanti L, Boswell MV, Singh V, Derby R, Fellows B, Falco FJE, Datta S, Smith HS, Hirsch JA. Comprehensive review of neurophysiologic basis and diagnostic interventions in managing chronic spinal pain. Pain Physician 2009; 12:E71-E120.

30. Manchikanti L, Boswell MV, Singh V,
Benyamin RM, Fellows B, Abdi S, Buenaventura RM, Conn A, Datta S, Derby R, Falco FJE, Erhart S, Diwan S, Hayek SM, Helm S, Parr AT, Schultz DM, Smith HS, Wolfer LR, Hirsch JA. Comprehensive evidence-based guidelines for interventional techniques in the management of chronic spinal pain. Pain Physician 2009; 12:699-802.

31. Manchikanti L, Derby R, Wolfer LR, Singh V, Datta S, Hirsch JA. Evidencebased medicine, systematic reviews, and guidelines in interventional pain management: Part 5. Diagnostic accuracy studies. Pain Physician 2009; 12:517-540.

32. Manchikanti L, Derby $R$, Wolfer LR, Singh V, Datta S, Hirsch JA. Evidencebased medicine, systematic reviews, and guidelines in interventional pain management: Part 7: Systematic reviews and meta-analyses of diagnostic accuracy studies. Pain Physician 2009; 12:929-963.

33. Bossuyt PM, Reitsma JB, Bruns DE, Gatsonis CA, Glasziou PP, Irwig LM, Lijmer JG, Moher D, Rennie D, de Vet HC; STARD Group. Towards complete and accurate reporting of studies of diag nostic accuracy: The STARD initiative. Fam Pract 2004; 21:4-10. 